Filol. Linguíst. Port., São Paulo, v. 17, n. 2, p. 675-693, jul./dez. 2015

http://dx.doi.org/10.11606/issn.2176-9419.v17i2p675-693

\title{
Dispositivos comunicacionais e produção de imaginários: o caso dos periódicos científicos
}

\section{Communicational devices and the production of imaginaries: the case of scientific journals}

\author{
Luciana Salazar Salgado* \\ Universidade Federal de São Carlos, São Carlos, São Paulo, Brasil \\ Letícia Moreira Clares** \\ Universidade Federal de São Carlos, São Carlos, São Paulo, Brasil
}

\begin{abstract}
Resumo: No quadro da Análise do Discurso de tradição francesa (AD), propomos neste artigo uma reflexáo que parte da noção de dispositivo desenvolvida recentemente por Jean-Jacques Courtine (2013) para estudar os formulários de revisão por pares das revistas do Instituto de Estudos Brasileiros (IEB/USP) e do Programa de Pós-Graduação em Geografia da Faculdade de Filosofia, Letras e Ciências Humanas (FFLCH/USP), GEOUSP: Espaço e Tempo, com vistas a observar como, nesse tipo de material, (re)constroem-se imaginários de ciência a partir do modo como os processos editoriais acontecem e caracterizam a comunicação científica, nos liames do que Dominique Maingueneau (2006) considera uma instituição discursiva. Partindo das reflexões desenvolvidas até o momento na pesquisa intitulada Ritos genéticos editoriais e comunicação cientifica: a atividade de revisão em periódicos, explicitamos a configuração desses periódicos como dispositivos comunicacionais e, para tanto, alguns indícios da constituição desses imaginários nos ritos genéticos editoriais adotados nos processos de mediação editorial dos periódicos estudados. Pretendemos, então, investigar algumas das dimensões da mediação editorial que balizam os imaginários de ciência e póem em circulação pública o conhecimento acadêmico.
\end{abstract}

«? *Professora adjunta no Departamento de Letras da UFSCar, São Carlos, SP, Brasil, lucianasalazarsalgado@gmail.com.

** Mestranda no Programa de Pós-Graduação em Linguística, PPGL, UFSCar, leticia.clares@ gmail.com. 
Palavras-chave: Periódicos científicos. Dispositivos comunicacionais. Mediaçâoo editorial. Comunicação científica. Ritos genéticos editoriais. Imaginários.

\begin{abstract}
From the French tradition of discourse analysis (AD), this article aims at reflecting upon notes of journal's peer review forms from the Instituto de Estudos Brasileiros (IEB/USP) and the Graduate Program in Geography of FFLCH-USP, GEOUSP: Espaço e Tempo, mobilizing the notion of device recently developed by Jean-Jacques Courtine (2013). It focuses the imaginary of science which is (re)built up from the way the editorial processes occurs and characterizes the scientific communication, weaving what Dominique Maingueneau (2006) considers as a discursive institution. On the basis of considerations of the research entitled Editorial genetic rites and scientific communication: a review of activity in journals, this work intended to highlight the configuration of these journals as communicative devices. Therefore, some evidences are presented of the constitution of this imaginary by showing some editorial genetic rites adopted in the journal's editorial mediation processes. So far, this investigation proves that some dimensions of the editorial mediation are guided by the imaginary of science which puts academic knowledge into public circulation.
\end{abstract}

Keywords: Scientific journals. Communicational devices. Editorial mediation. Scientific communication. Editorial genetic rites. Imaginary

\title{
1 FLUXOS DE TEXTO E RITOS DE EDIÇÃO
}

Este artigo parte de um entendimento do atual período como caracterizado pela constante multiplicação de objetos que impulsionam novos ritmos de produção, circulação e consumo de diversos bens e serviços - e, portanto, de imaginários que lhes dão sentido e sustentação:

A aceleração contemporânea impôs novos ritmos ao deslocamento dos corpos e ao transporte das ideias, mas também acrescentou novos itens à história. Junto com uma nova evolução das potências e dos rendimentos, com o uso de novos materiais e de novas formas de energia, o domínio mais completo do espectro eletromagnético, a expansão demográfica (a população mundial triplica entre 1650 e 1900 , e triplica de novo entre 1900 e 1984), a expansão urbana e a explosão do consumo, o crescimento exponencial do número de objetos e do arsenal de palavras. Mas, sobretudo, causa próxima ou remota de tudo isso, a 
evolução do conhecimento, maravilha do nosso tempo que ilumina ou ensombrece todas as facetas do acontecer (Santos, 1997, p. 1).

Assim, entendemos que fazem parte dessa aceleração contemporânea os fluxos de texto e, nesse mercado de trocas dos materiais linguísticos em circulação pública, verifica-se que a comunicaçáo em rede e as tecnologias digitais desestabilizaram práticas de produção editorial até então efetivas, demandando aos estudos da mediação editorial a redefinição de algumas categorias: "textos estão ligados a diversos tipos de materialidade" e, dadas "as mutaçóes contemporâneas da cultura escrita", vemos que "a textualidade digital abala as categorias e práticas que eram as fundaçóes para a ordem dos discursos" (Chartier, 2014, p. 11-13). Nesse sentido, entendemos que refletir sobre tais práticas é também refletir sobre os objetos que as suscitam, o que permite abordar não apenas o funcionamento de um conjunto de técnicas e normas voltadas à produção de livros, revistas e outras publicaçóes, mas sobretudo sua relação com as esferas da economia e da cultura, dimensóes irredutíveis dos objetos discursivos.

Considerando o cenário atual da chamada comunicação científica, no qual se instaura uma política de publicar para de fato validar o conhecimento produzido na academia, os periódicos científicos vêm se configurando como peças-chave dos jogos de poder que mobilizam o funcionamento da ciência como a conhecemos hoje (Cf. Gruszynski et al., 2008). Além de registrar, consagrar e disseminar pesquisas, a busca por reconhecimento e visibilidade propiciada por instrumentos tem suscitado discussôes por parte de agências de regulamentação e fomento como a Coordenação de Aperfeiçoamento de Pessoal de Nível Superior (CAPES), o Conselho Nacional de Desenvolvimento Científico e Tecnológico (CNPq) e a Scientific Electronic Library Online (SciELO), responsáveis por financiar pesquisas, avaliar e qualificar periódicos e programas de pós-graduação e, assim, condicionar diversas das atividades acadêmicas dependentes desses processos de valoração.

Desse modo, frequentemente as equipes editoriais de periódicos científicos têm sido chamadas a rever questóes relacionadas a seus expedientes, tanto mais no que diz respeito ao desenvolvimento da comunicação nas diversas áreas em que é posta como condição institucional de existência dos campos de saber. Uma dessas pautas, muitas vezes apresentada pela comunidade científica como um verdadeiro desafio para o sucesso das publicaçóes, é a contribuição de autores, editores e revisores.

Salgado, L.S.; Clares, L.M. Dispositivos comunicacionais e produção de imaginários... 
O que chama especialmente a atenção nesses coletivos de trabalho é a variação dos termos utilizados para designar quem avalia artigos submetidos à publicação - ora revisor, revisor ad hoc, ora parecerista, avaliador - e a própria atividade de avaliação - revisão, revisão por pares, parecer ou peer review -, instabilidade constatável em diversos casos específicos, como nos ambientes de edição de materiais didáticos, particularmente nos casos em que há transmidiações e adaptaçôes, como nas interfaces entre material impresso e áudio, nas quais denominaçôes e funções dos profissionais que dão tratamento ao texto se multiplicam e opacificam (Cf. Clares, 2013, por exemplo).

De fato, o estudo do funcionamento discursivo que preside o preparo de textos destinados à circulação pública exige lembrar que estão compreendidas aí tanto as práticas generalizadas nas casas editoriais quanto outras, menos oficiais, mas igualmente generalizadas, dos próprios autores, que frequentemente tomam a iniciativa de contratar uma revisão de textos antes mesmo de submeter seu material à apreciação de uma editora. E é preciso levar em conta também que se, por um lado, esse tipo de trabalho se intensificou recentemente e tem cada vez mais características peculiares ao nosso tempo (afinidades com a tecnologia informática, com a aceleração de processos dela decorrentes e com as urgências de produtividade e competitividade que impelem a alimentação desse ciclo), por outro, é herança de uma longa história que remonta a práticas anteriores até mesmo ao formato códex moderno, as quais revelam o quanto o original de um autor, no longo processo que o transforma em publicação, movimenta-se, passando por diferentes olhares e cuidados. A própria Classificação Brasileira de Ocupaçôes (CBO), frequentemente atualizada pelo Ministério do Trabalho e Emprego (MTE) e que organiza descrições de atividades profissionais por famílias, conjuntos de ocupaçóes estabelecidos pelo reconhecimento de semelhanças características de um domínio de trabalho mais amplo do que cada ocupação, numa tentativa de prever flexibilidades asseguradas por algum rigor de definição, prevê uma família "Profissionais da escrita”, bastante extensa e considerada próxima das chamadas famílias afins "filólogos, intérpretes e tradutores" e "editores", numa circunscrição de competências que sempre fazem fronteira com outras, sem que jamais se defina o que faz um revisor.

Em estudos recentes sobre o tratamento editorial de textos, vemos que se trata de considerar a revisão como uma das etapas de preparo dos textos para circulação pública, a qual é muito mais que uma leitura rigorosa na busca por apontar possíveis "desvios" gramaticais ou normativos de um autor que "terminou" seu texto. Essa etapa de trabalho reabre o texto para o próprio autor, configurando um novo olhar que levanta diversas questóes, que determinam, por exemplo, se

Salgado, L.S.; Clares, L.M. Dispositivos comunicacionais e produção de imaginários... 
esse texto corresponde ao que caracteriza uma adequada inscrição no meio onde circulará. Em outras palavras:

Não se trata apenas de correção, mas de aperfeiçoamento e adequação de um texto escrito, o que significa dizer que há regras de construçáo previstas e ditames a serem respeitados, mas também que esse "respeito" será guiado por noçôes menos precisas, ainda que igualmente importantes e constitutivas das diretrizes de correção de um texto; aperfeiçoar e adequar envolvem conhecimentos relativos ao objeto sobre o qual versa o texto, às características que o autor the atribui, ao estilo desse autor e ao público a que se destina o material elementos que se complexificam, uma vez que estabelecem entre si relaçôes variadas, implicando-se dinamicamente (Salgado, 2011, p. 160, grifos da autora).

Na comunicação científica e, mais especificamente, em publicações periódicas, observamos que se denomina também revisão outra atividade: trata-se de uma avaliação dos artigos por um viés que náo o linguístico-discursivo, mas da ordem da pertinência técnico-científica, atividade que também faz parte de um processo de preparação dos artigos destinados à publicação em revistas especializadas. Segundo Mabe (2009 apud Cyrino, 2014),

a publicação de um artigo em um periódico indexado acontece a partir de um processo conduzido pelas editoras e denominado ciclo editorial ("publishing cycle"), que envolve a troca de informaçóes entre autores, editores, revisores e leitores, bem como os agentes de distribuição e disponibilização do periódico. (grifo nosso)

Embora esse processo não esteja discriminado publicamente de maneira explícita pelas revistas, e efetivamente o volume de informaçóes disponíveis a respeito da produção seja, em geral, bastante reduzido, mesmo em seçóes como sobre a revista ou diretrizes para autores/revisores, temos verificado que ocorre de forma semelhante ao que conhecemos em outros ambientes de edição já estudados, isto é, constitui-se como um conjunto de etapas que variam de um coletivo de trabalho para outro e que, por estarem pouco definidas, são ainda mal compreendidas. Parece, entretanto, que, nesse contexto, a designação se complexifica mais, pois se o olhar técnico daqueles considerados pares de um autor (membros da comunidade científica legitimados pelo próprio ato de avaliar o artigo de um colega) é chamado

Salgado, L.S.; Clares, L.M. Dispositivos comunicacionais e produção de imaginários... 
de revisão, como definir nesse universo de publicaçóes o que conhecemos como revisão (ou revisão de textos) mais amplamente? A etapa de trabalho com os textos em seus aspectos definidores do objeto editorial acontece na produção de periódicos científicos? Como é designada, então, nesse meio?

Com vistas a contribuir para a compreensão desse universo de produção textual, delimitamos um corpus a partir do qual cremos poder abordar a problemática mais ampla: a Revista do Instituto de Estudos Brasileiros (IEB), que reúne em regime quadrimestral artigos, resenhas e documentos relacionados aos estudos brasileiros, e a GEOUSP: Espaço e Tempo, revista que publica artigos, notas de pesquisas de campo, resenhas críticas e notícias (informes) de encontros científicos que tratem de temas definidos por uma abordagem geográfica.

A Revista do IEB é um periódico multidisciplinar que circula em versões impressa e digital, o que exige de seu expediente especificidades para cada versão, já que os meios impresso e digital oferecem e demandam encaminhamentos editoriais diferentes, algumas vezes incompatíveis - por exemplo, quanto ao projeto gráfico, que nesse periódico tem de abrigar particularidades das diversas áreas do conhecimento que publica. Já a GEOUSP é um periódico do grande campo Geografia, que contempla materiais subdivididos, conforme a tradição disciplinar, em Geografia Física e Geografia Humana, e que recentemente passou a circular apenas na interface digital, tendo como desafio as adaptaçóes necessárias à diagramação nesse formato.

O interesse pelas duas revistas na atual conjuntura, além da diferença que poderá servir a futuras reflexóes (um periódico multidisciplinar e outro disciplinar), deve-se ao fato de ambas terem migrado recentemente para o Portal SIBiUSP e, desde então, lidarem com a necessidade de preparaçáo na plataforma do Sistema Eletrônico de Editoração de Revistas (SEER), software gratuito desenvolvido pelo Instituto Brasileiro de Informação em Ciência e Tecnologia (IBICT) a partir da tradução e personalização do Open Journal Systems (OJS) para construção e gestão de publicações periódicas digitais. A editoração de periódicos no SEER, recomendada pela CAPES, permite maior rapidez no fluxo de informaçóes e melhorias na avaliação da qualidade das revistas e na disseminação, divulgação e preservação de seus conteúdos segundo a adoção de padróes internacionais para periódicos on-line.

A partir da descrição desses objetos de estudo e da breve exposição das condiçôes de produção (Pêcheux, 2014 [1969]) de sua constituição, podemos notar a complexidade das dimensóes não explicitadas nos processos editoriais, as quais precisamos investigar para entender como se estabelecem as relaçóes de poder no 
campo científico (Cf. Bourdieu, 1983), que determina o que é publicado, de que forma e para quem, isto é, a inter-relação das categorias definidoras da produção, da circulação e do consumo desses materiais editoriais.

Nesta altura da pesquisa, isso implica compreender o funcionamento da mediação editorial nas revistas científicas, as quais mobilizam uma parcela fortemente delimitada do mercado editorial brasileiro e são chamadas a transitar entre o consenso e a resistência aos discursos normativos (Cf. Muniz Jr., 2010), que produzem efeitos de sentido sobre a comunicação e a divulgação do conhecimento científico, bem como influenciam nos modos e modelos de ciência vigentes.

Tomada como nicho (segmento restrito) do mercado editorial, a comunicação científica tem um funcionamento característico do que Maingueneau (2006, p. 53) considera uma instituição discursiva:

Os escritores produzem obras, mas escritores e obras são, num dado sentido, produzidos eles mesmos por todo um complexo institucional de práticas. Deve-se, assim, atribuir todo o peso à instituição discursiva, expressão que combina inextricavelmente a instituição como ação de estabelecer, processo de construção legítima, e a instituição no sentido comum de organização de práticas e aparelhos. (grifos nossos)

Levando em conta, pois, essa relação de práticas sociais e ambiente constitutivo, e considerando que participam do mercado editorial brasileiro todas as práticas e indivíduos que gerem esse espaço, entendemos a comunicação científica como parte desse ambiente de trocas. Assim, como um campo constituído também institucionalmente, no qual os periódicos científicos se inscrevem como mediadores de um espaço de coocorrência de escritas profissionais (de forma mais acentuada a escrita científica, embora existam paratextos e todo um espaço associado não necessariamente científico, que merecerá abordagem futura) e processos de edição, constituindo-se em um conjunto de práticas que estabelecem relações de força, isto é, que resultam da conjugação de normas e técnicas próprias constituintes daquilo que o historiador Roger Chartier refere em toda sua obra como a ordem dos livros (ver especialmente 1999).

Desse modo, numa abordagem da revisão como uma atividade de mediação editorial, investigamos de que forma esta se dá enquanto avaliaçáo por pares e tratamento linguístico-discursivo e em que medida se constitui a relação entre essas instâncias no ciclo editorial, em que consideramos 
o trabalho que é feito sobre os textos autorais que se preparam para ir a público como ritos genéticos editoriais, especificando a noção de Maingueneau, sem jamais perder de vista que ela trata dos ritos de uma gênese discursiva, ou seja, sem perder de vista que o trabalho do coenunciador editorial, assim como o do autor e de todos os que lidam com seu texto, é feito de um dado lugar discursivo. (Salgado, 2011, p. 155, grifos da autora)

Compreendendo, então, os ritos genéticos editoriais como um conjunto de procedimentos adotados no tratamento editorial de textos, pressupomos que a relação mediação editorial-condiçóes de produção dos periódicos em questão, dada a amostra trabalhada por meio dos formulários de revisão por pares, permite uma análise criteriosa de seus ritos, de modo que apreendamos o papel dessas revistas como dispositivos comunicacionais que "armazenam e fazem circular o conhecimento humano, articulando em seu entorno fatores econômicos, sociais, simbólicos, estreitamente relacionados a dinâmicas de poder e de disputas" (Gruszynski et al., 2008, p. 1).

\section{DISPOSITIVOS COMUNICACIONAIS, IMAGINÁRIOS DE CIÊNCIA}

Ao comentar sobre a oscilação do uso das expressôes semiologia da política, semiologia da mensagem política, semiologia política da expressão e semiologia histórica em sua obra, Courtine (2011, p. 150-151) justifica a proposição de uma semiologia histórica que, na composição contemporânea da análise do discurso, dê conta das relaçóes entre linguagem e imagem, materializadas nos objetos discursivos:

os discursos estão imbricados em práticas não verbais, o verbo não pode mais ser dissociado do corpo e do gesto, a expressão pela linguagem conjuga-se com aquela do rosto, de modo que não podemos mais separar linguagem e imagem. Senti, portanto, que analisar os discursos não podia mais se limitar a caracterizar um corpus, em seus diferentes níveis de funcionamento linguístico. Mas que correspondia a pensar e a descrever a maneira pela qual se entrecruzam - na materialidade do arquivo tanto quanto suporte "psíquico" das memórias coletivas e individuais - regimes e práticas, séries de enunciados e redes de imagens.

Salgado, L.S.; Clares, L.M. Dispositivos comunicacionais e produção de imaginários... 
Numa abordagem da relação entre corpo e discurso nas formas de fala pública, o que resultou na passagem de uma análise do discurso para uma história do corpo/rosto, Courtine (2011) define seu distanciamento da tradição saussuriana de estudo da semiologia, aproximando-se de outra, de natureza antropológica, baseada na identificação de indícios intuitivos como prática essencial para a compreensão de imagens - designada pelo historiador Carlo Ginzburg como um paradigma indiciário. Ginzburg (1989) mostra, pela descrição de casos de campos como a História da Arte (Morelli e a atribuição de autoria a obras de arte), a Psicanálise (Freud e o discurso do inconsciente) e a Literatura (a personagem Sherlock Holmes e seus parâmetros de investigação), que nas últimas décadas do século XIX uma preocupação semelhante à de Saussure estava presente nessas outras áreas, ao mesmo tempo que o Curso de Linguística Geral era escrito por alguns de seus discípulos. Para Ginzburg (1989, p. 150), trata-se de "pistas: mais precisamente sintomas (no caso de Freud), indícios (no caso de Sherlock Holmes), signos pictóricos (no caso de Morelli)".

Na perspectiva da comunicação científica, especificamente no que tange às publicaçóes periódicas, e considerando a semiologia histórica proposta por Courtine (2011), uma análise dos discursos que corresponda a "pensar e a descrever a maneira pela qual se entrecruzam [...] regimes e práticas, séries de enunciados e redes de imagens" (Courtine, 2011, p. 151) corresponde também a pensar esses indícios dos quais fala Ginzburg nos ritos genéticos editoriais adotados nos expedientes das revistas, bem como nas condiçóes de produção que definem os expedientes típicos dessa comunidade discursiva. Como "cada sociedade observa a necessidade de distinguir os seus componentes; mas os modos de enfrentar essa necessidade variam conforme os tempos e os lugares" (Ginzburg, 1989, p. 171), importam os imaginários apreendidos nessas condiçóes de produção do discurso científico: a comunicação científica como instituição discursiva mobiliza práticas e memórias sobre essas práticas na organização dos processos de edição que caracterizam, por exemplo, a revisão por pares, a revisão de textos e mesmo a produção dos manuais de instrução que direta ou indiretamente condicionam essas atividades - os manuais de normalização e checklists voltados aos revisores e preparadores, as instruções dos formulários de parecer dos avaliadores, os critérios de avaliação da CAPES e de indexação da SciELO e mesmo as diretrizes para os autores.

Será útil, aqui, mobilizar também a noção de memória discursiva, que reúne dois planos complementares: o da textualidade (memória intratextual) e o do interdiscurso (o discurso dominado pela memória de outros discursos) (Charaudeau e Maingueneau, 2014). Assim, consideramos que constituem esses imaginários o 
conjunto de memórias que se constrói nos diversos campos de saber que participam da comunicação científica, em suas formulaçôes explícitas e nos indícios que se podem recolher ao longo dos processos que a configuram.

Enquanto na revista GEOUSP: Espaço e Tempo lidamos com memórias que nos dizem o que se espera de artigos que tratem do campo da Geografia, que registra as duas frentes publicadas pela revista (a Física, que promove estudos sistematizados sobre a superfície terrestre como parte de uma ciência mais exata, e a Humana, dedicada à compreensão da interação entre a sociedade e o espaço geográfico), na Revista do Instituto de Estudos Brasileiros nos deparamos com memórias ainda mais diversas, já que se trata de uma revista multidisciplinar que atende às áreas de Literatura, Letras, História, Artes, Sociologia, Filosofia, Música, entre outras.

Ao se reconstruírem e se atualizarem, conforme a demanda da própria dinâmica do andamento das pesquisas publicadas, essas memórias contribuem para a formação não só de imaginários próprios da ciência (a ciência de uma área do saber em particular), mas de ciência na conjuntura atual, o que nos permite considerar os periódicos científicos como dispositivos comunicacionais. Apropriando-se da noção de dispositivo de Foucault, Courtine (2013, p. 131), ao dizer que "os dispositivos não são simplesmente modos de classificação dos objetos do saber ou aparatos do exercício de um poder, mas [...], além disso, instrumentos de produção do sujeito", permite uma abordagem dos materiais textuais em tela depreensível de uma série de práticas sociais que, em relação, produzem efeitos de sentido legitimadores dos lugares que instituem.

Acrescente-se que o dispositivo "não procede de uma única instituição, ou de uma de suas ramificaçóes, mas 'do jogo que ele estabeleceu' entre várias delas [...] E dentre elas, a ciência ela mesma” (Courtine, 2013, p. 129). Com base nisso, podemos entender que, como instrumentos e veículos dessas constantes (re) construçôes de imaginários, as revistas científicas estão, nessas condiçôes, a serviço de "um regime de visibilidade" (Courtine, 2013, p. 79) que compreende esse jogo de memórias estabelecido na comunicação científica como instituição discursiva e reunindo comunidades discursivas, vale dizer, tanto em sentido amplo, dos que se reúnem em torno de um grande campo, uma vertente, uma subárea etc., conforme as divisôes legitimadas em cada conjuntura, quanto em sentido restrito, pensando nas diversas comunidades discursivas que, em suas práticas, conferem heterogeneidade a cada uma dessas mais abarcantes.

Para situar a natureza dessas reflexões, apresentaremos os formulários de revisão por pares da Revista do IEB e da GEOUSP . Analisando as diferenças estruturais da organização de tais formulários, 
temos notícia da ordem da relevância de alguns aspectos para um e outro periódico, provável reflexo de questóes mais amplas e fundamentais referentes às áreas do conhecimento contempladas nos artigos que publicam. Também identificamos imaginários que sustentam um e outro formulário e uma relação entre eles, constitutiva da atividade de revisão por pares.

Temos, assim, quanto à categoria que consideramos indicativa de diretrizes para o revisor:

\section{Revista do IEB}

Avaliação | assinale uma ou mais alternativas

( ) O artigo apresenta uma reflexão original

( ) A bibliografia citada é adequada e atualizada

( ) O texto é bem redigido

( ) $\mathrm{O}$ texto tem repetições de palavras e expressões

( ) O texto poderia ser sintetizado

( ) $\mathrm{O}$ texto requer reestruturação

( ) $\mathrm{O}$ texto não cabe em uma revista de caráter multidisciplinar

( ) $\mathrm{O}$ texto não corresponde aos padrões de um artigo acadêmico

( ) Outros (especifique):

Solicitamos seus comentários sobre o artigo anexo, observando particularmente os seguintes pontos:

- Oportunidade e relevância do artigo

- Qualidade e rigor da argumentação

- Cumprimento dos objetivos a que se propõe

- Adequação entre a análise e os dados apresentados

$\mathrm{Na}$ Revista do IEB, os itens definidos em avaliação indicam uma análise não somente técnico-científica do artigo, mas também da ordem do linguístico, já que são apontadas questôes relativas à qualidade do que se entende 
por escrita científica (esta também constitutiva e constituída de imaginários que merecerão detalhamentos futuros).

Julgar se "o texto é bem redigido", se "tem repetiçóes de palavras e expressões", se "poderia ser sintetizado", se "requer reestruturação" ou se "não corresponde aos padrốes de um artigo acadêmico" não necessariamente importa para a garantia de um rigor técnico do conteúdo abordado pelo artigo, mas o condiciona na medida em que indica que o revisor deverá reconhecer no texto de seus pares os liames que o definam como um texto científico, e mais, como um texto que domina certos usos linguísticos característicos do(s) campo(s) de saber em que se inscreve, uma interlíngua (Cf. Maingueneau, 2008), e que, por isso, cabe ou não "em uma revista de caráter multidisciplinar" - aí a opção "Outros (especifique)" indica o grau de especificidade de apontamentos que o revisor poderia fazer, a depender $\mathrm{da}(\mathrm{s})$ área(s) do conhecimento à(s) qual(is) o texto pertence, já que se trata de um periódico multidisciplinar, o que não caberia definir entre as alternativas mais gerais apresentadas (por isso o uso de "especifique").

Assinalar, então, se "o artigo apresenta uma reflexão original" remonta a uma memória relativa aos objetivos do texto científico que almeja publicação: apresentar para a comunidade científica o que há de novo a ser dito sobre determinada área ou objeto de estudo, embora aqui sejam discutíveis as noções de "novo" e "original", especialmente da perspectiva da Análise do Discurso.

Nos apontamentos indicados na sequência desses critérios, ficam mais explícitas as diretrizes para uma análise técnica propriamente dita dos artigos, apontamentos estes mais precisos ("oportunidade e relevância do artigo"; "qualidade e rigor da argumentação"; "cumprimento dos objetivos a que se propóe"; "adequação entre a análise e os dados apresentados"), propostos como guia do comentário que será redigido pelo revisor, embora esteja implícito que os critérios definidos na avaliaçáo anterior também devam balizar esse comentário.

Na revista GEOUSP: Espaço e Tempo, por sua vez, as questóes propostas são mais direcionadas no sentido de solicitar ao revisor um apontamento mais preciso com relação à pertinência técnico-metodológica do artigo: 


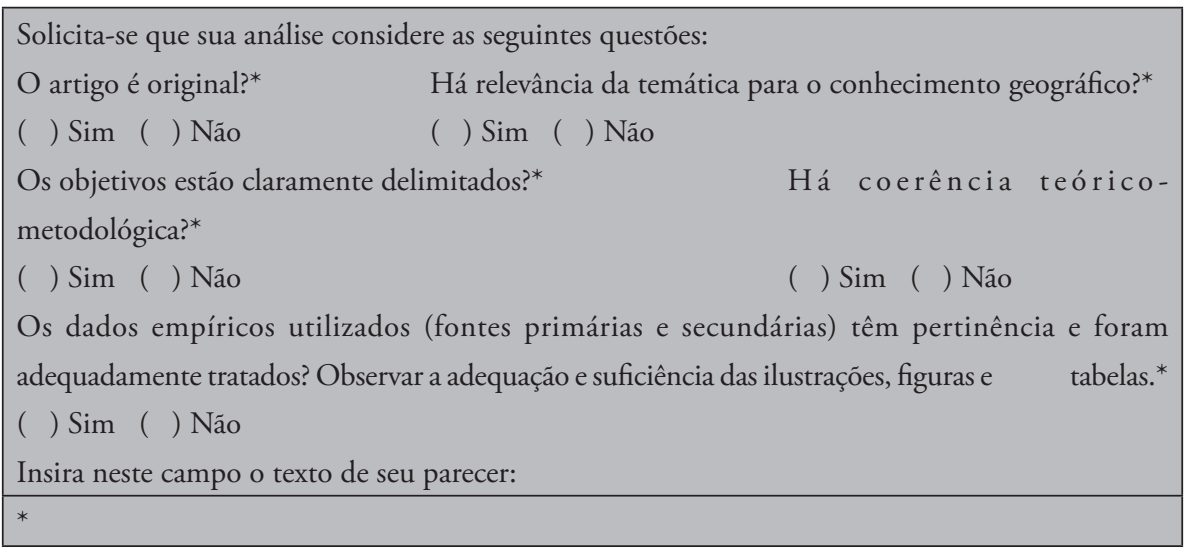

\section{GEOUSP: Espaço e Tempo}

Isso fica evidente pelo conteúdo das consideraçôes ("o artigo é original?"; "há relevância da temática para o conhecimento geográfico"; "há coerência teóricometodológica?"; "os dados empíricos utilizados [...] têm pertinência e foram adequadamente tratados?”), pela restrição das opçóes de resposta (sim ou não) e pelo asterisco $\left(^{*}\right)$ inserido em todas as questôes e que aparece novamente no final do formulário ("insira neste campo o texto de seu parecer: *"), indicando que essa análise deverá ser guiada especialmente pelas respostas dadas anteriormente às referidas questôes. Tal direcionamento provavelmente é mais eficiente no caso desse periódico, pelo fato de publicar artigos de uma única área do conhecimento, a Geografia, o que permite maior precisão das possibilidades de revisão no quesito contribuição para o campo.

Embora a revista aceite artigos de duas vertentes diferentes da Geografia, a Física, que promove estudos sistematizados sobre a superfície terrestre como parte de uma ciência, digamos, mais exata, e a Humana, dedicada à compreensão da interação entre a sociedade e o espaço geográfico, percebe-se a priorização de uma revisão mais técnica no âmbito das questôes que envolvem a atividade de pesquisa em si: a consideraçáo e o tratamento dos dados, a abordagem teórico-metodológica e a "comprovação" do que se diz ("observar a adequação e suficiência das ilustrações, figuras e tabelas") instauram uma semântica de análise categórica do texto, no sentido de apontar se é pertinente ou não como uma publicação de resultados que contribuam para o desenvolvimento da área - talvez um ponto predominante da Geografia Física, delimitada como uma ciência mais “dura”, em relação à Humana. 
Essas impressóes se reafirmam se observarmos nos formulários o espaço reservado à decisão do revisor sobre sua avaliação. Temos, então, quanto aos apontamentos do revisor:

\section{Revista do IEB}

\section{Recomendaçóes \\ ( ) Publicação sem revisão \\ ( ) Publicação somente após revisões substantivas (especificar) \\ ( ) Publicação após pequenas revisões estilísticas ou textuais (especificar)( ) Rejeição}

Considerando que ambos os formulários apresentam nesse campo pontos comuns abordados de maneiras diferentes, importam as formas como cada periódico espera que o revisor informe sua recomendação sobre a publicação ou não do artigo. Enquanto a Revista do IEB propóe publicação "sem revisão", "somente após revisóes substantivas" ou "após pequenas revisōes estilísticas ou textuais", a GEOUSP questiona se o artigo deve ser publicado "na forma atual", "com pequenas modificaçôes, conforme especificado" ou "desde que se procedam às modificaçôes especificadas". Solicitar do autor "revisóes substantivas" ou "revisóes estilísticas ou textuais" é diferente de solicitar "modificaçóes" ou "pequenas modificaçóes" especificadas e presume expedientes muito particulares de cada periódico, dadas as condições de produção referidas anteriormente.

No formulário da Revista do IEB temos, por contraste com a revisão por pares, a atividade de revisão de textos referida pontualmente ("revisão", "revisốes substantivas" e "revisóes estilísticas ou textuais"), o que indica a presença dessas duas atividades na produção editorial da revista, bem como sua dinâmica de funcionamento - a revisão de textos acontece na sequência da revisão por pares, mas é considerada como critério de garantia da publicação do artigo "pré-aprovado" 
("publicação somente após revisôes substantivas (especificar)"; "publicação após pequenas revisóes estilísticas ou textuais").

Já no formulário da GEOUSP, "pequenas modificações" e "modificações especificadas" não indicam explicitamente de que tipo de modificação se trata, mas "conforme especificado" e "modificaçóes especificadas" apontam para a autonomia do revisor de impor como condição de publicação do artigo qualquer tipo de modificação, o que inclui também a possibilidade de sugestôes da ordem do linguístico. Esse condicionamento, aliás, marcado em "o artigo deve ser publicado com pequenas modificações, conforme especificado" e "o artigo pode ser publicado desde que se procedam as modificaçóes especificadas", dá notícia do quão necessárias podem ser essas modificações, já que são critério de justificativa da recomendação ou não da publicação do texto submetido.

A partir desses apontamentos, podemos observar o quanto a problemática em torno dos periódicos científicos, tomados como dispositivos comunicacionais, requer um estudo não só dos ritos genéticos editoriais adotados nos processos de produção de revistas, mas desses ritos em relação aos critérios que os transcendem, na medida em que os condicionam ao mobilizar imaginários, por exemplo, de língua, de escrita, de ciência, de comunidade científica e, portanto, de comunicação científica, bem como de memórias sobre a produção e a disseminação do conhecimento científico dado como homogêneo.

Nesse cenário de demandas bastante específicas em que se instaura uma cultura de publicar para de fato validar o conhecimento produzido na academia, como um funcionamento fundante e legitimante da própria condição institucional, acreditamos que a importância de estudar os processos de edição de periódicos científicos e, para isso, compreender seus ritos genéticos editoriais, justifica-se pelo fato de se tratar de um importante dispositivo de disseminação e consolidação do conhecimento científico, ainda que somente entre os pares e não necessariamente a toda a sociedade, dispositivo este que

garante a memória da ciência, aponta seu grau de evolução, estabelece a propriedade intelectual, legitima novos campos de estudos e disciplinas, constitui-se em fonte para o início de novas pesquisas, dando visibilidade e prestígio aos 
pesquisadores entre um público altamente especializado, os seus pares. (Gruszynski et al., 2008, p. 4)

\section{CONSIDERAÇÓES FINAIS}

Considerando o referido cenário da comunicação científica, no qual lidamos com políticas organizacionais que preveem o dinamismo das publicaçôes como parâmetro de validação do universo das pesquisas, vemos que a abordagem dos periódicos científicos como dispositivos comunicacionais produtores de imaginários sobre a ciência, na medida em que se pretendem disseminadores do conhecimento científico, permite entendê-los como dispositivos de poder tanto da disseminação cada vez mais especializada do conhecimento quanto da validaçâo de procedimentos apoiados em imaginários de ciência, os quais são constantemente reconstruídos ao firmar seu valor e, na mesma mão, o valor dos lugares que os instituem justamente ao se articularem: o lugar de autor, o de editor, o de par, o de revisor...

Nesse sentido, encontramos nos formulários de parecer da GEOUSP e da RIEB indícios de um paralelo entre as atividades de revisão de textos e revisão por pares, pois ainda que as diretrizes para o parecer, dadas pela própria composiçáo estrutural do texto, apontem mais detidamente para um lugar de leitor e de revisor especializados (os pares), como na GEOUSP, revelam também um lugar de leitor profissional do texto, aquele que de saída fará "revisôes substantivas" ou "pequenas revisôes estilísticas ou textuais", conforme indicado pela RIEB. A marcação desses lugares mais ou menos assinalada evidencia um caráter, em geral, de má compreensão dos processos de mediaçáo editorial, tidos como um demérito, por exemplo, dos processos de autoria, como se o trabalho sobre o texto do outro fosse da ordem do ilegal e, por isso, devesse ser apagado ou camuflado.

Dando um passo adiante, cremos ser possível encaminhar a pesquisa desses periódicos e, mais amplamente, da comunicação científica, ensejando o entendimento de que a dispersão massiva do conhecimento produzida pelos periódicos científicos se opera na correlação de uma tecnoesfera crescentemente informacional, isto é, um conjunto de técnicas (e, portanto, uma série de objetos normatizadores e normalizadores) do qual emerge uma psicosfera, isto é, um conjunto de valores, crenças, emoçóes e toda sorte de subjetivaçooes produzidas em dinâmica (Cf. Santos, 2008, 2009). Digamos, por ora, que esses dispositivos comunicacionais permitem que uma perspectiva específica que tem valor "científico" ganhe mundo na conjuntura em que se produz e se dispersa. Isso nos remete a uma tese basal da análise do discurso: o que há não é a apresentação de um objeto no mundo, mas sua

Salgado, L.S.; Clares, L.M. Dispositivos comunicacionais e produção de imaginários... 
criação discursiva, e assim é que o objeto passa a fazer parte do mundo. A própria ideia de mundo é frequentemente recriada, dados os ritos e rituais coercitivos das convenções institucionalizadas e de outras, menos formalizadas, que se impóem na construção e atribuição de valor e efeitos simbólicos.

Disto se compõe uma psicoesfera de percepçóes do que seja o mundo, ao mesmo tempo em que se produz uma psicoesfera das redes de objetos técnicos em relação sistêmica que, conforme seus usos ou desusos, dispersam discursos, e, assim, valores, crenças etc., produzindo imaginários (Cf. Salgado, 2013). O batimento entre tecnoesfera e psicoesfera permite, assim, operar com outra noção basal da análise do discurso: as posições imaginárias que referem o jogo de projeções constitutivas dos lugares discursivos em que se instituem, como sujeitos, os atores que definem e legitimam os dispositivos (Cf. Gadet e Hak, 1997).

\section{REFERÊNCIAS}

Bourdieu P. O campo científico. In: Ortiz R, organizador. Pierre Bourdieu. São Paulo: Ática; 1983. p. 122-56.

Charaudeau P, Maingueneau D. Dicionário de análise do discurso. Fabiana Komesu, coordenadora de tradução. $3^{\mathrm{a}}$ ed., $1^{\mathrm{a}}$ reimp. Sáo Paulo: Contexto; 2014.

Chartier R. A mão do autor e a mente do editor. George Schlesinger, tradutor. São Paulo: Unesp; 2014.

Chartier R. A ordem dos livros: leitores, autores e bibliotecas na Europa entre os séculos XIV e XVIII. Mary Del Priori, tradutora. 2ª ed. Brasília: UNB; 1999.

Clares LM. A interface material impresso e audiolivro: o lugar do revisor de textos nos processos editoriais envolvidos. Sáo Carlos: PUICT/UFSCar; 2013. 59 p. Protocolo no $58 / 2012$.

Courtine JJ. Decifrar o corpo: pensar com Foucault. Francisco Morás, tradutor. Petrópolis: Vozes; 2013.

Courtine JJ. Discurso e imagens: para uma arqueologia do imaginário. In: Pionezanni C, Curcino L, Sargentini V, organizadores. Discurso, semiologia e história. São Carlos: Claraluz; 2011. p. 145-62.

Cyrino JEP. Revisões e revisores construtivos e eficazes [slide]. São José dos Campos: CEC-ABEC; 2014. 19 slides. [citado 20 jun. 2014]. Disponível em: http://www.abecbrasil.org. br/includes/eventos/xxii_curso/index.asp

Salgado, L.S.; Clares, L.M. Dispositivos comunicacionais e produção de imaginários... 
Gadet F, Hak T, organizadores. Por uma análise automática do discurso: uma introdução à obra de Michel Pêcheux. (reimpressão 2001). Diversos tradutores, rev. tecn. Eni Orlandi. 3a ed. Campinas: Editora da Unicamp; 1997.

Ginzburg C. Sinais: raízes de um paradigma indiciário. In: Ginzburg C. Mitos, emblemas, sinais: morfologia e história. Federico Carotti, tradutor. São Paulo: Cia das Letras; 1989. p. $143-80$.

Gruszynski AC, Golin C, Castedo R. Produção editorial e comunicação científica: uma proposta para edição de revistas científicas. E-compós. 2008 Maio/Ago;11(2):1-17.

Maingueneau D. Discurso literário. Adail Sobral, tradutor. São Paulo: Contexto; 2006.

Maingueneau D. Gênese dos discursos. Sírio Possenti, tradutor. São Paulo: Parábola Editorial; 2008.

Muniz Jr JS. O trabalho com o texto na produção de livros: os conflitos da atividade na perspectiva ergodialógica [dissertação]. São Paulo: Universidade de São Paulo, Escola de Comunicaçáo e Artes; 2010.

Orlandi EP. Discurso, imaginário social e conhecimento. Em Aberto. 1994;14(61):53-9.

Pêcheux M, Fuchs C. A propósito da análise automática do discurso: atualização e perspectivas. In: Gadet F, Hak T, organizadores. Por uma análise automática do discurso. Campinas: Editora da Unicamp; 1990 [1975]. p. 79-170.

Pêcheux M. Análise automática do discurso (AAD-69). In: Gadet F, Hak T, organizadores. Por uma análise automática do discurso: uma introduçáo à obra de Michel Pêcheux. Bethania Mariani et al., tradutores. $5^{\mathrm{a}}$ ed. Campinas: Unicamp; 2014. p. 59-158.

Salgado LS. Cibercultura: tecnoesfera e psicoesfera de alta potência difusora. In: Abriata VLR, Câmara NS, Rodrigues MG, Schwartzmann MN, organizadores. Leitura: a circulação de discursos na contemporaneidade. Franca: Unifran, 2013.

Salgado LS. Ritos genéticos editoriais: autoria e textualização. São Paulo: Fapesp/Annablume, 2011.

Santos M (1994). Técnica, espaço, tempo. Globalização e meio técnico-científico informacional. $5^{\mathrm{a}}$ ed. São Paulo: Edusp; 2008.

Santos M (2000). Por uma outra globalização - do pensamento único à consciência universal. $18^{\mathrm{a}}$ ed. São Paulo: Record; 2009.

Santos M. A aceleração contemporânea: tempo-mundo e espaço-mundo. In: Dowbor L, Ianni O, Resende PE, organizadores. Desafios da globalização. Petrópolis: Vozes; 1997. p. $1-5$. 
Rugoni LS. O imaginário do revisor de textos nos ritos genéticos editoriais [dissertação]. São Carlos: Universidade Federal de São Carlos, Programa de Pós-Graduação em Linguística; 2015.

Recebido em: 14/10/2015

Aprovado em: 07/12/2015

Salgado, L.S.; Clares, L.M. Dispositivos comunicacionais e produção de imaginários... 